\title{
Effect of maternal obesity on pregnancy outcomes and long-term metabolic consequences
}

\author{
Georgios Valsamakis, ${ }^{1}$ Evagelia L. Kyriazi, ${ }^{1}$ Zadalla Mouslech, ${ }^{1}$ \\ Charalampos Siristatidis, ${ }^{2}$ George Mastorakos ${ }^{1}$
}

\begin{abstract}
${ }^{1}$ Endocrine Unit, $2^{\text {nd }}$ Department of Obstetrics and Gynecology, Athens University Medical School, "Aretaieion" University Hospital; ${ }^{2} 3^{\text {rd }}$ Department of Obstetrics and Gynecology, University General Hospital Attikon, Athens, Greece
\end{abstract}

\section{INTRODUCTION}

Recent years have witnessed a worldwide increase in the prevalence of pre-pregnancy maternal obesity. A survey carried out in the USA between 2003 and 2006 reported that $32 \%$ of women aged 20-44 years were classified as obese (WHO 2009). ${ }^{1}$ The rise in obesity among pregnant women goes hand in hand with the upward trend of obesity in the general population. In addition, the percentage of women gaining excessive weight during pregnancy has also increased., ${ }^{2,3}$

The accumulation of intra-abdominal (visceral) fat, which obesity entails, results in a set of metabolic disorders. Obesity during pregnancy has detrimental effects on women's health because it is associated with increased risk for gestational diabetes mellitus (GDM), hypertension and preeclampsia. Furthermore, the increase of maternal obesity goes in parallel with the increase of birth weight. A study conducted in Denmark showed that mean birth weight increased by $45 \mathrm{~g}$, from $3474 \mathrm{~g}$ in 1990 to $3519 \mathrm{~g}$ in 1999. Moreover, the percentage of neonates heavier than $4000 \mathrm{~g}$ increased from $16.7 \%$ in 1990 to $20 \%$ in 1999. ${ }^{4}$ Similar results were published in the United States, with a mean increase of $116 \mathrm{~g}$ in birth weight

Address for correspondence:

George Mastorakos, 3 Neofytou Vamva Str.,

10674, Athens, Greece,

Tel.: +30 210 3636229, E-mail: mastorakg@ath.forthnet.gr

Received: 22-05-2014, Accepted: 30-01-2015 from 1975 to $2003 .{ }^{5}$ Increased birth weight has been mainly attributed to increased neonatal adiposity at birth ${ }^{6}$ which in turn is predictive of increased adiposity in childhood. ${ }^{7}$ Maternal pre-gravid obesity is considered as the strongest predictor of childhood obesity $^{7}$ and is postulated to create an adverse endometrial environment which predisposes the offspring to obesity, diabetes and cardiovascular disease in later life. Gestational weight gain is also a potential risk factor for childhood obesity. ${ }^{8}$ These findings may partially explain the spectacular increase of childhood and adolescent overweight and obesity in our time. ${ }^{9}$

There is large body of literature exploring maternal obesity and its short- and long-term consequences on the offspring. ${ }^{10-16}$ Several systematic reviews and meta-analyses confirm the association of pre-pregnancy overweight/obesity with the risk for high birth weight (HBW), large-for-gestational-age (LGA) neonates, macrosomia and subsequent offspring overweight/ obesity, ${ }^{17,18}$ while others provide limited evidence to support the aforementioned association. ${ }^{19}$ Furthermore, there are still important gaps in the literature that need to be assessed such as the pathophysiological mechanisms involving the maternal obesity effects with adverse pregnancy outcomes and future metabolic consequences for the fetus; the development of markers or algorithms for early prediction (from the beginning of pregnancy) of these adverse pregnancy outcomes, such as gestational diabetes and preeclampsia; establishment of criteria and cor- 
responding management for the pregnancy-acquired weight in specific groups at risk (e.g. pregnant women with pre-pregnancy BMI $>40$ ). Lastly, there are no interventional randomized controlled studies which associate the effect of maternal pre-pregnancy weight with pregnancy outcomes.

This nonsystematic review investigates the effect of pre-gravid and pregnancy-acquired (excessive gestational weight gain) maternal obesity upon pregnancy outcomes and its long-term consequences on offspring morbidity. An effort has been made to unfold the potential pathophysiological mechanisms underpinning the programming of obesity and of the resulting cardiometabolic disorders in adulthood. Finally, in order to increase the awareness of clinicians about the deleterious role of maternal pregnancyacquired weight, current knowledge regarding the management of maternal weight during pregnancy is included. Thus, the aim of this review is to draw conclusions useful for clinicians from the published epidemiological and pathophysiologic studies.

\section{Methods}

A search strategy was developed for PubMed; the algorithm was the following: (maternal obesity OR pre-pregnancy weight OR gestational weight gain) AND (pregnancy outcomes OR complications OR birth weight OR long-term metabolic effects) AND (Obesity management in pregnancy). No restrictions pertaining to publication language or study design were adopted. Reference lists of relevant articles were hand-searched for potentially eligible studies ("snowball" procedure) so as to maximize the amount of synthesized evidence. Interventional, prospective and retrospective studies, in vitro and animal studies, narrative and systematic reviews and meta-analyses were included.

\section{ADIPOSE TISSUE IN PREGNANCY}

In the last decade, a plethora of data have indicated that adipose tissue is not just an energy storage depot but rather a metabolically active tissue. ${ }^{20}$ The adipokines produced by the adipose tissue, such as leptin, adiponectin, resistin, visfatin, TNF- $\alpha$, IL- 6 and $\mathrm{RBP}-4$ exert paracrine as well as endocrine effects on a variety of target tissues. Adipokines are directly and/ or indirectly involved in reproduction, inflammation, immunity, insulin sensitivity and glucose homeostasis, lipid metabolism, blood pressure regulation, as well as appetite and energy balance. ${ }^{21}$ In addition, obesity, which denotes excessive accretion of fat, is now recognized as a low-grade chronic inflammatory disease and is associated with increased levels of CRP, TNF- $\alpha$ and IL-6. ${ }^{21,22}$ It has also been established that adipose tissue is extensively infiltrated by macrophages in the obese..$^{21,23}$ It has been suggested that this inflammation may be the result of obesity-derived hypoxia characterizing adipocytes distant from the capillary network as fat mass expands prior to angiogenesis. ${ }^{21}$

To the chronic inflammatory state of pre-gravid obesity must be added the accumulation of macrophages and pro-inflammatory mediators found in the placenta of obese women. ${ }^{24}$ In addition, substantial changes take place in fat distribution during pregnancy. A prospective study conducted by Sidebottom et al examined body weight and subcutaneous body fat by measuring skinfold thickness at the mid-thigh, triceps and subscapular sites before conception, once at each trimester and once at postpartum in 557 healthy women. ${ }^{25}$ They found that subcutaneous fat starts to accumulate around the sixth post-conception week and continues to increase through the 36th week of pregnancy. Women gained higher amounts of central body fat in the subscapular area and this fat was reduced to a lesser extent within the first six months postpartum than the peripheral stores of subcutaneous fat at the thigh and triceps. Of note, parity seems to play a significant role in fat distribution. Increasing parity is associated with a decrease in hip and thigh circumferences and an increase in waist circumference, which is a crude surrogate measure of visceral adiposity. ${ }^{26,27}$ Finally, a fair number of studies provide evidence that childbearing may be an important contributor to the enlargement of the intra-abdominal fat depot. Pregnancy is thought to be associated with preferential accumulation of adipose tissue in the visceral compartment. ${ }^{28}$ Regarding the differences in fat distribution observed between lean and obese pregnant women, it seems that the latter gain more fat in the central body compartment compared to the former, who gain more fat in the lower part of the body. ${ }^{29}$ 


\section{ADIPOSE TISSUE AND INSULIN RESISTANCE DURING PREGNANCY}

Visceral adiposity is associated with obesity-related insulin resistance, cardiovascular disease, lower HDL-cholesterol levels and progression to type 2 diabetes, particularly among women..$^{28,30}$ The increase of insulin resistance during gestation is paralleled by the progressive increase of maternal adipose tissue deposition. ${ }^{26}$ Pregnancy per se is a physiological state of insulin resistance. In fact, increasing insulin resistance in the liver, muscle and adipose tissue during pregnancy is of great importance because it enables the transfer of glucose and other nutrients to the fetus. This is mainly achieved through the placental hormones, such as human placental lactogen and human placental GH, as well as prolactin, cortisol and progesterone, which antagonize insulin. Compensatory hyperinsulinaemia follows insulin resistance increase during pregnancy. Failure of this adaptive mechanism leads to GDM. ${ }^{31}$ Obese women are significantly more insulin resistant than lean and overweight women, especially before conception and in early pregnancy (12-14 weeks). ${ }^{32}$ Pre-gravid insulin resistance coupled with inadequate insulin secretion during pregnancy results in the increased prevalence of GDM in women who are overweight or obese before conception. ${ }^{33-36}$ It is worth noting that GDM is associated with many adverse pregnancy outcomes. Compared to non-obese and non-GDM women, women with GDM face an increased odds ratio (OR) of 2.19 for birth weight $>90^{\text {th }}$ percentile. Odds ratios for primary caesarean delivery, preeclampsia, cord C-peptide and newborn percent body fat $>90^{\text {th }}$ percentile were similar (OR: 1.25, 1.74, 2.49, 1.98, respectively) ${ }^{37}$ Moreover, women who develop GDM have a considerably higher risk of developing type 2 diabetes mellitus within the following fifteen years. ${ }^{38}$

\section{CLINICAL ASSESSMENT OF WEIGHT IN PREGNANCY}

\section{Relationship between pre-pregnancy weight and pregnancy outcomes - Table 1}

As already mentioned, numerous studies have reported an increased risk of GDM among women who are overweight or obese before conception as compared to thin or normal weight women. A meta- analysis of twenty studies showed that the risk for developing GDM is increased 3.6 times in obese and 8.6 times in severely obese women compared to normal weight women. ${ }^{34}$ Similarly, obese women are at increased risk for gestational hypertension and preeclampsia. ${ }^{32}$ According to a large prospective multi-center study including 16,102 women, obese women were 2.5 and 1.6 times more likely to develop gestational hypertension and preeclampsia, respectively, than women with a BMI of less than $30 \mathrm{~kg} / \mathrm{m}^{2}$ before pregnancy. ${ }^{35}$ These results are confirmed by the HAPO study, which demonstrated that higher prepregnancy BMI, independent of maternal glycaemia, is associated with greater likelihood of preeclampsia, caesarian delivery and higher neonatal birth weight and body fat. ${ }^{39}$ More specifically, according to a metaanalysis summarizing evidence on the relationship between maternal obesity and caesarean delivery, it was shown that caesarean delivery risk is increased by $50 \%$ in overweight women and it is encountered twice more often in obese compared with normal weight women. ${ }^{40}$

Increased pre-gravid weight is also related to certain congenital anomalies. Compared with mothers with recommended BMI, obese mothers are at increased risk of pregnancies affected by neural tube defects (OR 1.87), including spina bifida (OR 2.24), cardiovascular abnormalities (OR 1.3) including septal anomalies (OR 1.2), cleft palate (OR 1.23), cleft lip and palate (OR 1.2), anorectal atresia (OR 1.48), hydrocephaly (OR 1.68) and, finally, limb reduction anomalies (OR 1.34). ${ }^{41}$

Both maternal overweight and obesity have been associated with an increased risk of infant mortality in term births due to increased mortality risk in term births and an increased prevalence of preterm births. ${ }^{42}$

In addition, maternal pre-gravid obesity is associated with a significantly increased risk for a low Apgar score ( $<7$ at 5 minutes after birth). A population study including 369,347 women in Denmark reported that the OR for having a neonate with a low Apgar score was 1.3, 1.4 and 1.9 in overweight, obese and severely obese women, respectively, compared with women of normal weight. ${ }^{33}$ In the same study, it was shown that the risk for stillbirth (intrauterine death occurring after 22 completed weeks of gestation) was 


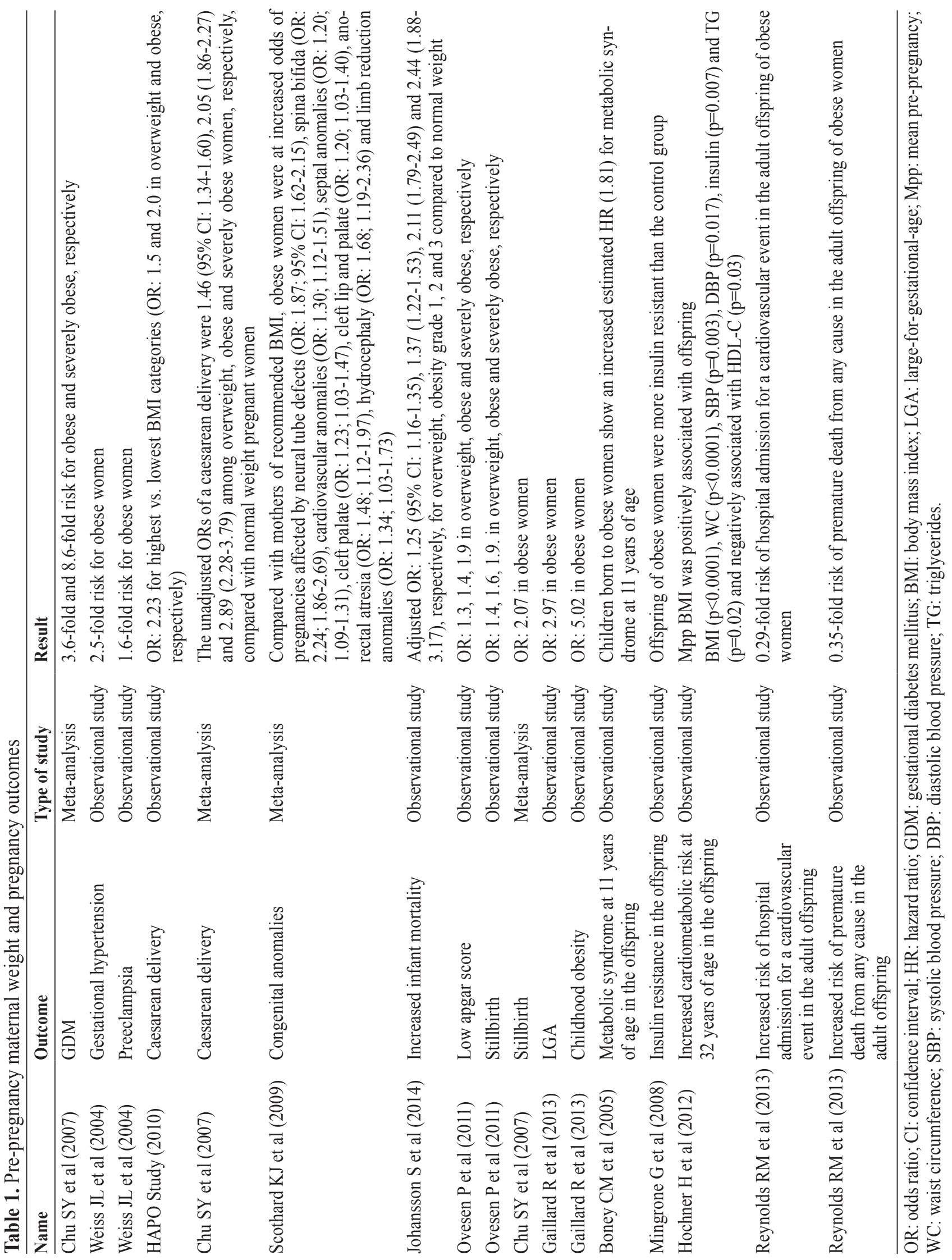


increased by $40 \%, 60 \%$ and $90 \%$ in overweight, obese and severely obese women, respectively, compared with women of normal BMI ${ }^{33}$. Similar results were published in a meta-analysis by Chu et al who estimated the OR of stillbirth at 2.07 in obese women compared with normal weight pregnant women. ${ }^{43}$ Finally, pre-gravid obesity has been associated with a 3-fold risk of delivering LGA neonates and a 5-fold risk of childhood obesity. ${ }^{44,17}$

\section{Relationship between weight gain during pregnancy and pregnancy outcomes - Table 2}

Apart from pre-gravid weight status, the role of gestational weight gain is also under meticulous investigation due to its postulated effect on several adverse pregnancy outcomes.

The majority of studies show some degree of association between higher gestational weight gain and caesarean delivery, with the risk of caesarean delivery being more pronounced among overweight and obese women. ${ }^{45}$ Excessive weight gain during pregnancy is an independent risk factor for caesarean delivery, even if birth weight is lower than $4 \mathrm{~kg}$. Pregnant women who put on excessive weight have an OR of 1.4 for caesarean delivery. ${ }^{46}$

Of note, both high and low weight gains are associated with increased risk for preterm birth. ${ }^{45}$ It has also been found that there is a positive correlation between gestational weight gain and birth weight, especially among underweight and normal weight women. In addition, increased weight gain during pregnancy is considered to be a risk factor for macrosomia. ${ }^{45}$ There is large body of literature corroborating the association between increased gestational weight gain and LGA neonates. ${ }^{45,47}$ Simas et al demonstrated that normal weight, overweight and obese women who gain excessive weight during pregnancy have an OR for LGA of 1.76, 2.9 and 1.55, respectively. ${ }^{48}$ Interestingly, maternal weight gain during pregnancy seems to influence the weight status of the offspring far beyond neonatal life. There is evidence supporting a positive association between increased gestational weight gain and risk of childhood overweight in the offspring. ${ }^{49,50}$ According to a large multi-ethnic cohort study, the odds of overweight at the age of 7 was $48 \%$ greater for children whose mothers gained more than the weight gain recommendations (the study refers to the Institute of Medicine guidelines of 1990) than for children whose mothers met the weight gain guidelines. ${ }^{50}$ Furthermore, it has been demonstrated that gestational weight gain is associated with BMI and risk of obesity in adolescence and early adulthood. ${ }^{51,52}$ More specifically, it has been shown that young adults at 21 years of age are at greater risk of becoming overweight or obese if their mothers had gained excessive weight during pregnancy. ${ }^{52}$

Additionally, a cohort study which included 481 obese, glucose-tolerant women demonstrated that increasing gestational weight gain increased the risk of hypertension, caesarean section, induction of labour and macrosomia. ${ }^{53}$

There is also a considerable body of literature examining the relationship between increased gestational weight gain and disorders in glucose metabolism. Saldana et al found that increased weight gain during pregnancy was associated with impaired glucose tolerance among overweight women. ${ }^{54}$ Excessive gestational weight gain, particularly in early pregnancy, has been associated with an increased risk of GDM $.55,56$ A retrospective cohort study which included 652 women (163 with GDM and 489 controls) also showed that women who develop GDM have higher gestational weight gain through 24 weeks. The same study showed that gestational weight gain is a risk factor for GDM in overweight and obese patients, but not in those who were underweight or of normal weight before pregnancy. ${ }^{57}$

Of note, women who gain excess weight during pregnancy are at greater risk of becoming overweight or obese ${ }^{58}$ and of being diagnosed with diabetes mellitus in later life. ${ }^{59}$

Crane et al have shown that in women with a normal pre-pregnancy BMI, excessive weight gain is associated with increased rates of gestational hypertension (OR 1.27), augmentation of labour (OR 1.09) and birth weight $\geq 4000 \mathrm{~g}$ (OR 1.21) ${ }^{60}$ Furthermore, in overweight women, increased weight gain is associated with increased rates of gestational hypertension (OR 1.31 ) and birth weight $\geq 4000 \mathrm{~g}$ (OR 1.30$).{ }^{60}$ Finally, in obese or morbidly obese women, excessive weight gain is associated with increased prevalence of birth weight $\geq 4000$ gr (OR 1.2) and neonatal metabolic abnormality (OR 1.31). ${ }^{60}$ 
Table 2. Gestational maternal weight gain and pregnancy outcomes

\begin{tabular}{|c|c|c|c|}
\hline & Outcome & Type of study & Result \\
\hline $\begin{array}{l}\text { Viswanathan } M \text { et } \\
\text { al (2008) }\end{array}$ & $\begin{array}{l}\text { Caesarean } \\
\text { delivery }\end{array}$ & Meta-analysis & Moderate evidence \\
\hline $\begin{array}{l}\text { Stotland NE et al } \\
(2004)\end{array}$ & $\begin{array}{l}\text { Caesarean } \\
\text { delivery }\end{array}$ & $\begin{array}{l}\text { Observational } \\
\text { study } \\
\text { Retrospective } \\
\text { cohort study }\end{array}$ & OR: 1.40 (95\% CI: $1.22-1.59)$ for women with excessive weight gair \\
\hline
\end{tabular}

Jensen DM et al Gestational

(2005) hypertension

Viswanathan $\mathrm{M}$ et Preterm birth

al (2008)

Viswanathan $\mathrm{M}$ et Macrosomia al (2008)

Simas TAM et al LGA

(2012)

Vesco KK et al LGA

(2014)

Oken E et al

(2007)

Oken E et al

(2008)

Al Mamun A et al (2009)

Saldana TM et al IGT-GDM (2006)

Henderson MM et IGT-GDM al (2010)

Morisset AS et al (2011)

Gibson KS et al (2012)

Al Mamun A et al (2010)

Al Mamun A et al (2013)
Obesity in adolescence

Obesity in young adulthood

IGT-GDM

IGT-GDM

Overweight/Obesity in later life (for the mothers)

$\mathrm{DM}$ in later life (for the mothers)
Meta-analysis

Increasing weight gain in obese women was associated with significantly higher rates of hypertension (OR 4.8; 95\% CI: 1.7-13.1), caesarean section (OR: $3.5 ; 1.6-7.8)$, induction of labour (OR: $3.7 ; 1.7-8.0)$ and large-for-gestational-age infants (OR: 4.7; 2.0-11.0)

Meta-analysis Strong evidence supported an association between gestational weight gains and preterm birth

Meta-analysis Strong evidence supported an association between gestational weight gains and macrosomia

Meta-analysis

Excessive GWG associated with increased odds of LGA. Adjusted OR: 1.76 (95\% CI: 1.38-2.24), 2.99 (1.92-4.65) and 1.55 (1.10-2.19) for normal weight, overweight and for obese women, respectively

Interventiona study

Observational study

Intervention participants gained less weight and had a lower proportion of LGA babies ( 9 vs. 26\%; OR: 0.28; 95\% CI: 0.09-0.84)

Greater than IOM recommendations weight gain was associated with higher child BMI z-score (0.13 units per $5 \mathrm{~kg}$; 95\% CI: 0.08-0.19)

Compared with inadequate weight gain, women with adequate or excessive weight gain had children with higher BMI z-scores $[0.47$ (0.37-0.57) and 0.52 (0.44-0.61), respectively] and OR for overweight children $3.77(1.38-10.27)$ and 4.35 (1.69-11.24), respectively

Observational Women with excessive weight gain had children with higher BMI study Z-scores (0.14 units, $95 \%$ CI 0.09-0.18) and risk of obesity [OR: 1.42 (1.19-1.70)]

Observational At 21 years of age, offsprings' BMI was on average $0.3 \mathrm{~kg} / \mathrm{m}^{2}(95 \%$ study

Observational study

Observational study

Observational study

Observational study

Observational study CI: $0.1-0.4$ ) higher for each $0.1 \mathrm{~kg} / \mathrm{wk}$ greater GWG after adjustment for potential confounding factors

Weight gain during pregnancy was associated with IGT only among overweight women

Rates of weight gain from $0.27-0.40 \mathrm{~kg} / \mathrm{wk}$ and $0.41 \mathrm{~kg} / \mathrm{wk}$ or more, were associated with increased risks of GDM [OR: $1.43 ; 95 \% \mathrm{CI}$ : $0.96-2.14$; and $1.74 ; 1.16-2.60$, respectively]

First trimester weight gain was a significant and independent predictor of GDM [OR: 1.25; 95\% CI 1.10-1.42)

Maternal weight gain was higher $(\mathrm{P}<.001)$ in the GDM group $(14.8$ lb) than in the control group $(11.2 \mathrm{lb})$

Increased OR for women with excess weight gain during pregnancy to become overweight $(2.15 ; 95 \% \mathrm{CI}: 1.64-2.82)$ or obese $(4.49 ; 3.42$ 5.89) 21 years after the index pregnancy

Observational 1.47-fold (1.11-1.94) risk for mothers with excess weight during pregstudy nancy to experience diabetes at 21 years postpartum compared to mothers with adequate weight gain

OR: odds ratio; CI: confidence interval; GWG: gestational weight gain; LGA: large-for-gestational-age; IOM: institute of medicine; BMI: body mass index; IGT: impaired glucose tolerance; GDM: gestational diabetes mellitus; DM: diabetes mellitus. 
The influence of maternal obesity on fetal development and its long-term metabolic effects

Fetal growth and development depend on the equilibrium in the interaction of the triad mother placenta - fetus. Fetal development is not only determined by the fetal genome but is also influenced by the endometrial environment. Apart from placental growth and function and the external environment, the endometrial environment is also formed by maternal related factors. These include maternal metabolism and its changes during pregnancy, maternal dietary habits and anthropometrics as well as the mother's psychological, behavioural and personality characteristics.

All of the abovementioned factors seem to induce persistent alterations of gene expression through epigenetic changes in the fetus, which may lead to several metabolic and neurodevelopmental disorders later in adult life. This adaptive process of the fetus when a stimulus is applied in utero is called fetal programming. Thus, obesity during pregnancy creates an abnormal milieu in utero and leads to fetal-neonatal obesity, which is considered to be associated with childhood and adult obesity as well as type 2 diabetes and metabolic syndrome in adulthood.

The association between maternal obesity and fetal macrosomia has been established by many studies. ${ }^{61,17}$ Overweight or obese women with normal glucose tolerance levels give birth to heavier neonates compared to lean or normal weight women, apparently because of increased adiposity. ${ }^{6}$ In line with this finding, Hull et al found that neonates born to normal weight mothers have significantly less total and relative fat and more fat-free mass than neonates born to overweight or obese mothers. ${ }^{62}$ Decreased maternal insulin sensitivity, which is the common denominator in obese women and women with GDM, is also related to fetal overgrowth. In particular, decreased maternal insulin sensitivity before conception appears to have the strongest correlation with fetal fat mass at term. ${ }^{63}$ Both maternal over-nutrition and maternal glucose intolerance are associated with elevated fetal plasma glucose and insulin concentrations and increased leptin secretion in fetal adipose tissue. Hyperglycaemia, hyperinsulinaemia and hyperleptinaemia act on central neurons in the energy balance regulating system, causing alterations in appetite and adipocyte metabolism and high neonatal adiposity. It is postulated that the early origins of childhood and adulthood obesity lie in these alterations occurring during fetal life. ${ }^{64}$ Epigenetic modifications in response to over-nutrition may lead to metabolic imprinting or permanent alterations in genes involved in the regulation of energy homeostasis. Several such genes have been shown to be regulated by DNA methylation and histone modifications, including genes for leptin, ${ }^{65} \mathrm{SOCS}^{66}$ and glucose transporter. ${ }^{67}$ Recently, Bouchard et a ${ }^{68}$ found maternal hyperglycaemia to be correlated with placental leptin gene DNA methylation levels. Animal studies have shown that metabolic imprinting caused by the obese intrauterine environment can actually be transmitted across generations (trans-generational cycle of obesity).$^{69}$ These findings suggest that the intrauterine environment of diabetic and obese women may impact the epigenome of the offspring.

Indeed, a retrospective cohort study showed that among children whose mothers were obese in the first trimester of pregnancy, the prevalence of obesity at ages two, three and four years was $15.1 \%, 20.6 \%$ and $24.1 \%$, respectively. This was 2.4 to 2.7 times higher than the prevalence of obesity among children of normal weight mothers. The calculated relative risk for childhood obesity resulting from first trimesterassociated maternal obesity at two, three and four years of age was 2.0, 2.3 and 2.3, respectively. ${ }^{70}$

It has also been shown that pre-pubertal LGA-born children are more insulin resistant than matched AGA (appropriate for gestational age) controls, although they have a higher mean serum adiponectin level (adiponectin is considered as an insulin-sensitizing adipokine). Moreover, pre-pubertal LGA-born children $>97$ th percentile have a significantly higher mean serum leptin level than AGA (leptin is considered to increase insulin sensitivity). ${ }^{71,72}$ On the other hand, Darendeliler et al have found that LGA children have higher insulin and lower adiponectin levels than AGA children in spite of similar BMI. ${ }^{73}$ A study enrolling 52 young adult offspring of obese mothers and 15 offspring of normal weight mothers demonstrated that the former are more likely to be obese and develop insulin resistance than the latter. ${ }^{74}$ Of note, higher maternal pre-pregnancy BMI has been associated with higher offspring systolic and diastolic blood pressure, insulin and triglyceride levels and lower HDL cholesterol at 32 years of age. ${ }^{75}$ Reynolds et 
al have recently extended these results by finding a $29 \%$ increased risk of hospital admission for a cardiovascular event in the adult offspring of obese mothers compared with the offspring of mothers with normal BMI. ${ }^{76}$ Likewise, the former exhibit a 35\% increased risk of premature death from any cause, compared with the latter. ${ }^{76}$

\section{Other pathophysiological mechanisms linking maternal obesity to increased cardiometabolic risk in offspring}

Both animal and human studies have suggested a number of mechanisms, apart from hyperinsulinaemia and hyperleptinaemia, linking maternal obesity to the increased incidence of obesity and cardiometabolic diseases in offspring. In ewes, maternal obesity upregulates fatty acid and glucose transporters and increases expression of enzymes mediating fatty acid biosynthesis in fetal adipose tissue depots. ${ }^{77}$ Human studies using magnetic resonance imaging have shown that maternal BMI predicts infant intrahepatocellular lipid storage, as seen in animal models, which implies that maternal obesity may predispose the offspring to developing nonalcoholic fatty liver, the hepatic manifestation of metabolic syndrome. ${ }^{78,79}$ Furthermore, maternal obesity appears to downregulate fetal myogenesis. Skeletal muscle is the principal site for glucose and fatty acid utilization. Thus, maternal obesity might result in decrease of the offspring's skeletal muscle mass and changes of its properties, eventually increasing their risk for the development of type 2 diabetes and obesity. ${ }^{80,81}$ Regarding the programming of vascular function and blood pressure, studies in rats highlighted the presence of endothelial dysfunction in the offspring of obese mothers, while studies in rodents demonstrated that the offspring of obese females develop hypertension and increased cardiovascular response to stress due to increased sympathetic activity. ${ }^{82}$ In addition, studies in human full-term placentas showed that maternal obesity impacts placental fatty acid uptake and could therefore modify the fetus metabolism and the child's predisposition to develop diseases later in life. ${ }^{83} \mathrm{Ma}-$ ternal obesity leads to a lipotoxic placental environment that is associated with decreased regulators of angiogenesis and increased markers of inflammation and oxidative stress. ${ }^{84}$ This environment via in utero programming may trigger adaptive pathways which ultimately result in increased percentage of body fat and propensity for future obesity in the offspring of obese women..$^{85}$

\section{MANAGEMENT OF WEIGHT DURING PREGNANCY}

As underlined earlier in this review, maternal prepregnancy BMI and gestational weight gain are two factors of great importance for pregnancy outcome. The increasing prevalence of overweight and obesity among women of childbearing age and the rising percentage of women gaining too much weight during pregnancy necessitated the revision of the Institute of Medicine (IOM) guidelines of 1990. In 2009, the IOM published new guidelines for recommended weight gain during pregnancy according to the maternal pregravid BMI. Thus, IOM recommends a weight gain of $12.5-18 \mathrm{~kg}$ for women of BMI $<18.5 \mathrm{~kg} / \mathrm{m}^{2}, 11.5$ $16 \mathrm{~kg}$ for women of BMI $18.5-24.9 \mathrm{~kg} / \mathrm{m}^{2}, 7.5-11.5$ $\mathrm{kg}$ for women of BMI $25-29.9 \mathrm{~kg} / \mathrm{m}^{2}$ and $5-9 \mathrm{~kg}$ for women of BMI $\geq 30 \mathrm{~kg} / \mathrm{m}^{2}$ (Table 3). The committee formulated these guidelines taking into consideration not only the welfare of the child but also the health of the mother and aiming at optimal pregnancy outcome. IOM recommendations provide useful guidance for monitoring weight during pregnancy in order to avoid fetal and maternal complications.

A different approach regarding weight gain during pregnancy has been suggested by a Swedish study of 298,648 singleton pregnancies conducted by Cedergren who proposed that the optimal gestational weight gain based on pre-pregnancy BMI was 4-10 kg for BMI less than $20 \mathrm{~kg} / \mathrm{m}^{2}, 2-10 \mathrm{~kg}$ for BMI $20-24.9 \mathrm{~kg} / \mathrm{m}^{2}$, less than $9 \mathrm{~kg}$ for BMI $25-29.9 \mathrm{~kg} / \mathrm{m}^{2}$ and less than $6 \mathrm{~kg}$ for BMI of $30 \mathrm{~kg} / \mathrm{m}^{2}$ or more. ${ }^{86}$

Table 3. IOM 2009 recommendations for total weight gain during pregnancy, by pre-pregnancy BMI. ${ }^{53}$

\begin{tabular}{cc}
\hline $\begin{array}{c}\text { Pre-gestational BMI } \\
\left(\mathbf{k g} / \mathbf{m}^{2}\right)\end{array}$ & $\begin{array}{c}\text { Recommended gestational } \\
\text { weight gain }(\mathbf{k g})\end{array}$ \\
\hline$<18.5$ & $12.5-18$ \\
$18.5-24.9$ & $11.5-16$ \\
$25-29.9$ & $7.5-11.5$ \\
$\geq 30$ & $5-9$ \\
\hline
\end{tabular}


Health professionals should debunk the myth that pregnant women should "eat for two". Nevertheless, a pregnant woman has to increase her dietary energy intake in order to compensate for the increase of BMR and the energy deposited in fetal and maternal tissues as pregnancy progresses. It has been estimated that the energy needs of a normal weight pregnant woman do not significantly change in the first trimester, but increase by $350 \mathrm{kcal}$ per day in the second trimester and by $500 \mathrm{kcal}$ per day in the third trimester. ${ }^{87}$

There is no real difference between what constitutes a healthy diet during pregnancy and a healthy diet at any time in life. Thus, following IOM recommendations, $45-65 \%$ of a pregnant woman's energy intake should come from carbohydrates, $20-35 \%$ from fat and $10-35 \%$ from proteins. ${ }^{88}$ A low glycaemic index diet in pregnancy appears to have a significant positive effect on gestational weight gain and maternal glucose intolerance, although it does not reduce the incidence of large-for-gestational-age infants in women at risk for fetal macrosomia (having previously delivered an infant weighing more than $4 \mathrm{~kg}$ ). ${ }^{89}$ However, a low glycaemic index diet intervention in pregnancy was found to have a beneficial effect on neonatal central adiposity. ${ }^{90}$ According to the NICE (National Institute for Health and Care Excellence) guidelines, pregnant women should base their meals on starchy foods, eat at least five portions of vegetables and fruits each day and consume fibre-rich foods instead of foods rich in fat and sugar. Notably, it has been shown that extreme sugar intakes among pregnant adolescents may lead to increased accretion of fetal abdominal fat with little net effect, however, on birth weight. ${ }^{91}$

Pregnant women should also be physically active and incorporate at least 30 minutes of moderateintensity activity into each day. However, women who did not exercise regularly before pregnancy should begin with no more than 15 minutes of continuous activity three times per week, gradually reaching a target of 30 minutes. ${ }^{92}$

Moreover, women with a BMI $\geq 30 \mathrm{~kg} / \mathrm{m}^{2}$ should be informed about the risks their weight poses to themselves and to their child in the event of pregnancy. Health professionals should help these women reduce their weight before becoming pregnant by providing them with an individualized weight loss programme built around on a balanced nutrient-rich diet along with exercise. ${ }^{92}$ Obese pregnant women should be encouraged to adopt a healthy lifestyle built around the principles which were outlined earlier. A dietary intervention study for limiting gestational weight gain among obese women showed that intervention participants gained less weight and had a lower prevalence of LGA neonates..$^{47}$ Moreover, dietary interventions are the most effective type of intervention in pregnancy in reducing gestational weight gain and the risks of pre-eclampsia, gestational hypertension and shoulder dystocia.${ }^{93}$ Losing weight during pregnancy is not recommended because it may harm the health of the unborn child. ${ }^{92,94}$ Restrictive diets may increase blood ketone levels and could adversely affect the neurocognitive development of the fetus. ${ }^{92}$

The IOM committee recommmends a gestational weight gain range of 5-9 $\mathrm{kg}$ for all obese women and does not stratify its recommendations by severity of obesity. However, the optimal gestational weight gain for obese women, especially for those of class II (BMI $35-39.9 \mathrm{~kg} / \mathrm{m}^{2}$ ) and class III (BMI $\geq 40 \mathrm{~kg} / \mathrm{m}^{2}$ ) obesity, is a matter of ongoing debate among researchers. Hinkle et al suggest that gestational weight gains below the IOM guidelines for obese women with $\mathrm{BMI} \geq 35$ $\mathrm{kg} / \mathrm{m}^{2}$ may reduce the risk of excessive fetal growth without restricting fetal development..$^{95}$ Moreover, it has been found that gestational weight gain of 2.2 $\mathrm{kg}$ to less than $5 \mathrm{~kg}$ for obese class III white women is associated with probabilities of less than $10 \%$ for SGA and LGA births and a minimal risk of preterm delivery. ${ }^{96}$ These results raise the question of whether more restrictive weight gain limitations could be set for severely obese pregnant women.

\section{STRENGTHS AND LIMITATIONS}

The main strength of this review should be considered the effort exerted to relate results of basic and clinical studies regarding the influence of maternal pre-pregnancy and gestational weight gain upon the development of future pathologic entities in the offspring with everyday practice concerning the management of these women during pregnancy in order to decrease the aforementioned pathology risks. Data on dietary management and its effects on maternal weight gain and neonatal outcomes has 
also been included. A limitation of this review is failure to provide a systematic review. This is due, in part, to the type of published research literature available and its lack of homogeneity. In particular, there is a paucity of interventional randomized controlled studies examining the impact of maternal pre-pregnancy weight and gestational weight gain upon pregnancy outcomes. Some interventional studies aiming at limiting gestational weight gain and evaluating pregnancy outcomes have been included. Because pre-pregnancy maternal weight was selfreported or obtained by recall in some studies, the risk of bias in them is present. Finally, based on the included studies, it is difficult to distinguish the true causal relationship between maternal obesity and offspring obesity from confounding factors such as maternal age, ethnicity, smoking during pregnancy, educational level, etc. because it is not clear whether some studies had adjusted for the possible presence of these confounders. To eliminate this weakness, there is a need for randomized controlled intervention trials to assess the effects of pre-pregnancy maternal weight as well as of gestational maternal weight gain on maternal metabolism and neonatal outcomes.

\section{CONCLUSIONS}

Obesity constitutes one of the most serious health challenges of the 21 st century. The prevalence of adverse pregnancy outcomes is increased among women who are overweight or obese before conception and women who gain excessive weight during gestation. Obese mothers give birth to heavier neonates who are more likely to be obese as children and are at greater risk of developing metabolic disorders in later life. For all these reasons, it is very evident that women should have normal weight when entering pregnancy and should keep their gestational weight gain within the recommended range according to the IOM guidelines of 2009. Obesity engenders obesity and the need to put an end to this vicious cycle is imperative. Nutritional counseling for establishment of a healthy and balanced diet, physical exercise and close monitoring of maternal weight preconceptionally and throughout pregnancy can be useful weapons in our battle against the current epidemic of obesity.

\section{REFERENCES}

1. Heslehurst N, Ells LJ, Simpson H, Batterham A, Wilkinson J, Summerbell CD, 2007 Trends in maternal obesity incidence rates, demographic predictors, and health inequalities in 36821 women over a 15 -year period. BJOG 114: 187-194.

2. Institute of Medicine/National Research Council (Committee to Reexamine IOM Pregnancy Weight Guidelines, Food and Nutrition Board and Board on Children, Youth and Families) 2009 Weight gain during pregnancy: reexamining the guidelines. Washington, DC; National Academies Press.

3. Schiessl B, Beyerlein A, Lack N, von Kries R, 2009 Temporal trends in pregnancy weight gain and birth weight in Bavaria 2000-2007: slightly decreasing birth weight with increasing weight gain in pregnancy. J Peninat Med 37: 374-379.

4. Orskou J, Kesmodel U, Henriksen TB, Secher NJ, 2001 An increasing proportion of infants weigh more than $4000 \mathrm{~g}$ at birth. Acta Obstet Gynecol Scand 80: 931-936.

5. Catalano PM, 2007 Management of Obesity in Pregnancy. Obstet Gynecol 109: 419-433.

6. Sewell MF, Huston-Presley L, Super DM, Catalano P, 2006 Increased neonatal fat mass,not lean body mass, is associated with maternal obesity. AJOC 195: 11001103.

7. Catalano PM, Farrell K, Thomas A, et al, 2009 Perinatal risk factors for childhood obesity and metabolic dysregulation. Am J Clin Nutr 90: 1303-1313.

8. Lau EY, Liu J, Archer E, McDonald SM, Liu J, 2014 Maternal Weight Gain in Pregnancy and Risk of Obesity among Offspring: A Systematic Review. J Obes [ Epub ahead of print].

9. Ogden CL, Flegal KM, Carrol MD, Johnson CL, 2002 Prevalence and trends in overweight among US children and adolescents. JAMA, 288: 1728-1732.

10. Sirimi N, Goulis DG, 2010 Obesity in pregnancy. Hormones (Athens) 9: 299-306.

11. Ruager-Martin R, Hyde MJ, Modi N, 2010 Maternal obesity and infant outcomes. Early Hum Dev 86: 715722.

12. Vasudevan C, Renfrew M, McGuire W, 2011 Fetal and perinatal consequences of maternal obesity. Arch Dis Child Fetal Neonatal Ed 96: 378-382.

13. McGuire W, Dyson L, Renfrew M, 2010 Maternal obesity: consequences for children, challenges for clinicians and carers. Semin Fetal Neonatal Med 15: 108-112.

14. Papachatzi E, Dimitriou G, Dimitropoulos K, Vantarakis A, 2013 Pre-pregnancy obesity: maternal, neonatal and childhood outcomes. J Neonatal Perinatal Med 6: 203-216.

15. Galliano D, Bellver J, 2013 Female obesity: short- and long-term consequences on the offspring. Gynecol 
Endocrinol 29: 626-631.

16. O'Reilly JR, Reynolds RM, 2013 The risk of maternal obesity to the long-term health of the offspring. Clin Endocrinol (Oxf) 78: 9-16.

17. Yu Z, Han S, Zhu J, Sun X, Ji C, Guo X, 2013 Prepregnancy body mass index in relation to infant birth weight and offspring overweight/obesity: a systematic review and meta-analysis. PLoS One 8: 616-627.

18. Lawlor DA, Relton C, Sattar N, Nelson SM, 2012 Maternal adiposity--a determinant of perinatal and offspring outcomes? Nat Rev Endocrinol 8: 679-688.

19. Patro B, Liber A, Zalewski B, Poston L, Szajewska H, Koletzko B, 2013 Maternal and paternal body mass index and offspring obesity: a systematic review. Ann Nutr Metab 63: 32-41.

20. Catalano PM, 2003 Editorial: Obesity and pregnancyThe propagation of a viscous cycle? J Clin Endocrinol Metab 88: 3505-3506.

21. Trayhurn P, 2005 Review Endocrine and signalling role of adipose tissue:new perspectives on fat. Acta Physiol Scand 184: 285-293.

22. Festa A, D’Agostino R Jr, Williams K, et al, 2001 The relation of body fat mass and distribution to markers of chronic inflammation. Int J Obes 25: 1407-1415.

23. Weisberg SP, McCann D, Desai M, Rosenbaum M, Leibel RL, Ferrante AW Jr, 2003 Obesity is associated with macrophage accumulation in adipose tissue. J Clin Invest 112: 1796-1808.

24. Challier JC, Basu S, Bintein T, et al, 2008 Obesity in pregnancy stimulates macrophage accumulation in the placenta. Placenta 29: 274-281.

25. Sidebottom AC, Brown JE, Jacobs DR Jr, 2001 Pregnancy-related changes in body fat. Eur J Obst Gynecol Reprod Biol 94: 216-223.

26. Valsamakis G, Kumar S, Creatsas G, Mastorakos G, 2010 The effects of adipose tissue and adipocytokines in human pregnancy. Ann N Y Acad Sci 1205: 76-81.

27. Lassek WD, Gaulin SJ, 2006 Changes of body fat distribution in relation to parity in american women:a covert form of maternal depletion. Am J Phys Anthropol 131: 295-302.

28. Gunderson EP, Sternfeld B, Wellons MF, et al, 2008 Childbearing may increase visceral adipose tissue independent of overall increase in body fat. Obesity 16: 1078-1084.

29. Soltani H, Fraser RB, 2000 A longitudinal study of maternal anthropometric changes in normal weight,overweight and obese women during pregnancy and postpartum. Br J Nutr 84: 95-101.

30. Albu JB, Murphy L, Frager DH, Johnson JA, Pi-Sunyer FX, 1997 Visceral fat and race-dependent health risks in obese nondiabetic premenopausal women. Diabetes 46: 456-462.

31. Gardner DG, Shoback D 2011 Greenspan's Basic \& Clinical Endocrinology. In: Gardner DG, Shoback D (eds) Lange clinical medicine, McGraw-Hill Medical,
New York p; 650.

32. Catalano PM, Ehrenberg HM, 2006 The short- and long-term implications of maternal obesity on the mother and her offspring. BJOC 113: 1126-1133.

33. Ovesen P, Rasmussen S, Kesmodel U, 2011 Effect of prepregnancy maternal overweight and obesity on pregnancy outcome. Obstet Gynecol 118: 305-312.

34. Chu SY, 2007 Maternal obesity and risk of gestational diabetes mellitus. Diabetes Care 30: 2070-2076.

35. Weiss JL, Malone FD, Emig D, et al, 2004 Consortium, FASTER Research. Obesity, obstetric complications and cesarean delivery rate - a population based screening study. Am J Obstet Gynecol 190: 1091-1097.

36. Nohr EA, Vaeth M, Baker JL, et al, 2008 Combined associations of prepregnancy body mass index and gestational weight gain with the outcome of pregnancy. Am J Clin Nutr 87: 1750-1759.

37. Catalano PM, McIntyre HD, Cruickshank JK, et al, 2012 HAPO Study Cooperative Research. The hyperglycemia and adverse pregnancy outcome study: associations of GDM and obesity with pregnancy outcomes. Diabetes Care 35: 780-786.

38. Linne Y, Barkeling B, Rossner S, 2002 Natural course of gestational diabetes mellitus:long term follow-up of women in the SPAWN study. BJOG 109: 1127-1131.

39. HAPO Study Cooperative Research Group 2010 HAPO study: associations with maternal body mass index. BJOC 117: 575-584.

40. Chu SY, Kim SY, Schmid CH, et al, 2007 Maternal obesity and risk of caesarean delivery: a meta-analysis. Obes Rev 8: 385-394.

41. Stothard KJ, Tennant PWG, Bell R, Rankin J, 2009 Maternal overweight and obesity and the risk of congenital anomalies. A systematic review and meta-analysis. JAMA 301: 636-650.

42. Johansson S, Villamor E, Altman M, Bonamy AK, Granath F, Cnattingius S, 2014 Maternal overweight and obesity in early pregnancy and risk of infant mortality: a population based cohort study in Sweden. BMJ 349: g6572.

43. Chu SY, Kim SY, Lau J, et al, 2007 Maternal obesity and risk of stillbirth: a metaanalysis. Am J Obstet Gynecol 197: 223-228.

44. Gaillard R, Durmuş B, Hofman A, Mackenbach JP, Steegers EA, Jaddoe VW, 2013 Risk factors and outcomes of maternal obesity and excessive weight gain during pregnancy. Obesity 21: 1046-1055.

45. Viswanathan M, Siega-Riz AM, Moos MK, et al, 2008 Outcomes of maternal weight gain. Evid Rep Technol Assess 168: 1-223.

46. Stotland NE, Hopkins LM, Caughey AB, et al, 2004 Gestational weight gain,macrosomia and risk of cesarean birth in nondiabetic nulliparas. Obstet Gynecol 104: 671-677.

47. Vesco KK, Karanja N, King JC, et al, 2014 Efficacy of a group-based dietary intervention for limiting gestational 
weight gain among obese women: a randomized trial. Obesity 22: 1989-1996.

48. Simas TAM, Waring ME, Garrison A, et al, 2012 Prepregnancy weight,gestational weiht gain and risk of growth affected neonates. J Womens Health 21: 410417.

49. Oken E, Taveras EM, Kleinmann KP, et al, 2007 Gestational weight gain and child adiposity at age 3 years. Am J Obstet Gynecol 196: 322e1-322e8.

50. Wrotniak BH, Shults J, Butts S, Stettler N, 2008 Gestational weight gain and risk of overweight in the offspring at age $7 \mathrm{y}$ in a multicenter, multiethnic cohort study. Am J Clin Nutr 87: 1818-1824.

51. Oken E, Rifas-Shiman SL, Field AE, et al, 2008 Maternal gestational weight gain and offspring weight in adolescence. Obstet Gynecol 112: 999-1006.

52. Mamun AA, O'Callaghan M, Callaway L, Williams G, Najman J, Lawlor DA, 2009 Associations of gestational weight gain with offspring body mass index and blood pressure at 21 years of age: evidence from a birth cohort study. Circulation 119: 1720-1727.

53. Jensen DM, Ovesen P, Beck-Nielsen H, et al, 2005 Gestational weight gain and pregnancy outcomes in 481 obese glucose tolerant women. Diabetes Care 28: 2118-2122.

54. Saldana TM, Siega-Riz AM, Adair LS, et al, 2006 The relationship between pregnancy weight gain and glucose tolerance status among black and white women in central North Carolina. AJOG 195: 1629-1635.

55. Hedderson MM, Gunderson EP, Ferrara A, et al, 2010 Gestational weight gain and Risk of gestational Diabetes Mellitus. Obstet Gynecol 115: 597-604.

56. Morisset AS, Tchernof A, Dubé MC, Veillette J, Weisnagel SG, Robitaille J, 2011 Weight gain measures in women with GDM. J Womens Health (Larchmt) 20: 375-380.

57. Gibson KS, Waters TP, Catalano PM, 2012 Maternal weight gain in women who develop gestational diabetes mellitus. Obstet Gynecol 119: 560-565.

58. Mamun AA, Kinarivala M, O’Callaghan MJ, Williams GM, Najman JM, Callaway LK, 2010 Associations of excess weight gain during pregnancy with long-term maternal overweight and obesity:evidence from $21 \mathrm{y}$ post-partum follow-up. Am J Clin Nutr 91: 1336-1341.

59. Al Mamun A, Mannan M, O’Callaghan MJ, et al, 2013 Association between gestational weight gain and postpartum diabetes:evidence from a community based large cohort study. PLoS One 8: e75679.

60. Crane JM, White J, Murphy P, et al, 2009 The effect of gestational weight gain by body mass index on maternal and neonatal outcomes. J Obstet Gynaecol Can 31: 28-35.

61. Yogev Y, Catalano PM, 2009 Pregnancy and obesity. Obstet Gynecol Clin N Am 36: 285-300.

62. Hull HR, Dinger MK, Knehans AW, Thomson DM, Fields DA, 2008 Impact of maternal body mass index on neonate birthweight and body composition. Am J Obstet Gynecol 198: 416e1-416e6.

63. Catalano PM, Kirwan JP, Haugel-de Mouzon S, Kingzz J, 2003 Gestational diabetes and insulin resistance: Role in short and long-term implications for mother and fetus. J Nutr 133: 1674S-1683S.

64. McMillen IC, Edwards LJ, Duffield J, Muhlhausler BS, 2006 Regulation of leptin synthesis and secretion before birth: implications for the early programming of adult obesity. Reproduction 131: 415-427.

65. Melzner I, Scott V, Dorsch K, et al, 2002 Leptin gene expression in human preadipocytes is switched on by maturation-induced demethylation of distinct CpGs in its proximal promoter. J Biol Chem 277: 4542045427.

66. Campión J, Milagro FI, Martínez JA, 2009 Individuality and epigenetics in obesity. Obes Rev 10: 383-392.

67. Yokomori N, Tawata M, Onaya T, 1999 DNA demethylation during the differentiation of 3T3-L1 cells affects the expression of the mouse GLUT4 gene. Diabetes 48: 685-690.

68. Bouchard L, Thibault S, Guay SP, et al, 2010 Leptin gene epigenetic adaptation to impaired glucose metabolism during pregnancy. Diabetes Care 33: 2436-2441.

69. Dabelea D, Crume T, 2011 Maternal environment and the transgenerational cycle of obesity and diabetes. Diabetes 60: 1849-1855.

70. Whitaker RC, 2004 Predicting prescholar obesity at birth: the role of maternal obesity in early pregnancy. Pediatrics 114: 29-36.

71. Boney CM, Verma A, Tucker R, Vohr BR, 2005 Metabolic syndrome in childhood: association with birth weight, maternal obesity and gestational diabetes mellitus. Pediatrics 115: 290-296.

72. Giapros V, Evagelidou E, Challa A, Kiortsis D, Drougia A, Andronikou S, 2007 Serum adiponectin and leptin levels and insulin resistance in children born large for gestational age are affected by the degree of overweight. Clin Endocrinol (Oxf) 66: 353-359.

73. Darendeliler F, Poyrazoglu S, Sancakli O, et al, 2009 Adiponectin is an indicator of insulin resistance in non-obese prepubertal children born large for gestational age (LGA) and is affected by birth weight. Clin Endocrinol (Oxf) 70: 710-716.

74. Mingrone G, Manco M, Mora MEV, et al, 2008 Influence of maternal obesity on insulin sensitivity and secretion in offspring. Diabetes Care 31: 1872-1876.

75. Hochner H, Friedlander Y, Calderon-Margalit R, et al, 2012 Associations of maternal pre-pregnancy body mass index and gestational weight gain with adult offspring cardio-metabolic risk factors: the jerusalem perinatal family follow-up study. Circulation 125: 1381-1389.

76. Reynolds RM, Alan KM, Raja EA, et al, 2013 Maternal obesity during pregnancy and premature mortality from cardiovascular event in adult offspring: follow-up of 1323275 person years. BMJ 347: f4539. 
77. Long NM, Rule DC, Zhu MJ, Nathanielsz PW, Ford SP, 2012 Maternal obesity upregulates fatty acid and glucose transporters and increases expression of enzymes mediating fatty acid biosynthesis in fetal adipose tissue depots. J Anim Sci 90: 2201-2210.

78. Brumbaugh DE, Friedman JE, 2014 Developmental origins of nonalcoholic fatty liver disease. Pediatr Res 75: $140-147$.

79. Alfaradhi MZ, Fernandez-Twinn DS, Martin-Gronert MS, Musial B, Fowden A, Ozanne SE, 2014 Oxidative stress and altered lipid homeostasis in the programming of offspring fatty liver by maternal obesity. Am J Physiol Regul Integr Comp Physiol 307: 26-34.

80. Du M, Yan X, Tong JF, Zhao J, Zhu MJ, 2010 Maternal obesity, inflammation, and fetal skeletal muscle development. Biol Reprod 82: 4-12.

81. Tong JF, Yan X, Zhu MJ, Ford SP, Nathanielsz PW, Du M, 2009 Maternal obesity downregulates myogenesis and beta-catenin signaling in fetal skeletal muscle. Am J Physiol Endocrinol Metab 296: 917-924.

82. Drake AJ, Reynolds RM, 2010 Impact of maternal obesity on offspring obesity and cardiometabolic disease risk. Reproduction 140: 387-98.

83. Dubé E, Gravel A, Martin C, et al, 2012 Modulation of fatty acid transport and metabolism by maternal obesity in the human full-term placenta. Biol Reprod 87: 1-11.

84. Saben J, Lindsey F, Zhong Y, et al, 2014 Maternal obesity is associated with a lipotoxic placental environment. Placenta 35: 171-177.

85. Jarvie E, Hauguel-de-Mouzon S, Nelson SM, Sattar N, Catalano PM, Freeman DJ, 2010 Lipotoxicity in obese pregnancy and its potential role in adverse pregnancy outcome and obesity in the offspring. Clin Sci (Lond) 119: 123-129.

86. Cedergren MI, 2007 Optimal gestational weight gain for body mass index categories. Obstet. Gynecol 110: 759-764.

87. Butte NF, Wong WW, Treuth M, Ellis KJ, O’Brian Smith
E, 2004 Energy requirements during pregnancy based on total energy expenditure and energy deposition. Am J Clin Nutr 79: 1078-1087.

88. IOM. Dietary Reference Intakes for Energy, Carbohydrate. Fiber, Fat, Fatty Acids, Cholesterol, Protein, and Amino Acids (2002/2005). Washington, DC: National Academies Press.

89. Walsh JM, McGowan CA, Mahony R, Foley ME, McAuliffe FM, 2012 Low glycaemic index diet in pregnancy to prevent macrosomia (ROLO study): randomised control trial. BMJ 345: e5605.

90. Horan MK, McGowan CA, Gibney ER, Donnelly JM, McAuliffe FM, 2014 Maternal low glycaemic index diet, fat intake and postprandial glucose influences neonatal adiposity--secondary analysis from the ROLO study. Nutr J 13: 78.

91. Whisner CM, Young BE, Pressman EK, Queenan RA, Cooper EM, O’Brien KO, 2014 Maternal diet but not gestational weight gain predicts central adiposity accretion in utero among pregnant adolescents. Int $\mathbf{J}$ Obes (Lond) doi: 10.1038/ijo.2014.202 [Epub ahead of print].

92. NICE public health guidance, 2010 Weight management before, during and after pregnancy.

93. Thangaratinam S, Rogozińska E, Jolly K, et al, 2012 Coomarasamy A, Khan KS. Interventions to reduce or prevent obesity in pregnant women: a systematic review. Health Technol Assess 16: 1-191.

94. Hasegawa J, Nakamura M, Hamada S, et al, 2012 Gestational weight loss has adverse effects on placental development. J Matern Fetal Neonatal Med 25: 19091912.

95. Hinkle SN, Sharma AJ, Dietz PM, 2010 Gestational weight gain in obese mothers and associations with fetal growth. Am J Clin Nutr 92: 644-651.

96. Bodnar LM, Siega-Riz AM, Simhan HN, Himes KP, Abrams B, 2010 Severe obesity, gestational weight gain, and adverse birth outcomes. Am J Clin Nutr 91: 1642-1648. 